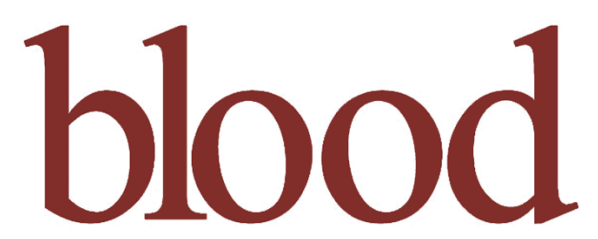

2005 105: 4445-4454

Prepublished online February 17, 2005;

doi:10.1182/blood-2004-10-3907

\title{
Mantle-cell lymphoma genotypes identified with CGH to BAC microarrays define a leukemic subgroup of disease and predict patient outcome
}

Fanny Rubio-Moscardo, Joan Climent, Reiner Siebert, Miguel A. Piris, Jose I. Martín-Subero, Inga Nieländer, Javier Garcia-Conde, Martin J. S. Dyer, Maria Jose Terol, Daniel Pinkel and Jose A. Martinez-Climent

Updated information and services can be found at: http://bloodjournal.hematologylibrary.org/content/105/11/4445.full.html

Articles on similar topics can be found in the following Blood collections Neoplasia (4217 articles)

Cell Adhesion and Motility (790 articles)

Oncogenes and Tumor Suppressors (795 articles)

Clinical Trials and Observations (3143 articles)

Information about reproducing this article in parts or in its entirety may be found online at: http://bloodjournal.hematologylibrary.org/site/misc/rights.xhtml\#repub_requests

Information about ordering reprints may be found online at:

http://bloodjournal.hematologylibrary.org/site/misc/rights.xhtml\#reprints

Information about subscriptions and ASH membership may be found online at: http://bloodjournal.hematologylibrary.org/site/subscriptions/index.xhtml

Blood (print ISSN 0006-4971, online ISSN 1528-0020), is published weekly by the American Society of Hematology, 2021 L St, NW, Suite 900, Washington DC 20036.

Copyright 2011 by The American Society of Hematology; all rights reserved.

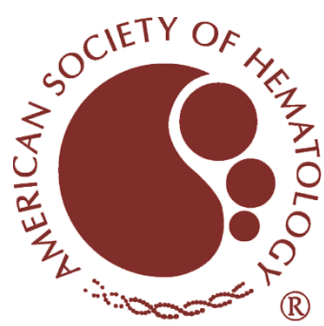




\section{Mantle-cell lymphoma genotypes identified with CGH to BAC microarrays define a leukemic subgroup of disease and predict patient outcome}

Fanny Rubio-Moscardo, Joan Climent, Reiner Siebert, Miguel A. Piris, Jose I. Martín-Subero, Inga Nieländer, Javier Garcia-Conde, Martin J. S. Dyer, Maria Jose Terol, Daniel Pinkel, and Jose A. Martinez-Climent

To identify recurrent genomic changes in mantle cell lymphoma (MCL), we used high-resolution comparative genomic hybridization (CGH) to bacterial artificial chromosome (BAC) microarrays in 68 patients and 9 MCL-derived cell lines. Array CGH defined an MCL genomic signature distinct from other B-cell lymphomas, including deletions of $1 \mathrm{p} 21$ and 11q22.3ATM gene with coincident 10p12-BMI1 gene amplification and 10p14 deletion, along with a previously unidentified loss within 9q21-q22. Specific genomic alterations were associated with different subgroups of disease. Notably, 11 patients with leukemic MCL showed a different genomic profile than nodal cases, including 8p21.3 deletion at tumor necrosis factor-related apoptosis-inducing ligand (TRAIL) receptor gene cluster $(55 \%$ versus $19 \% ; P=.01$ ) and gain of $8 \mathrm{q} 24.1$ at MYC locus (46\% versus $14 \% ; P=.015$ ). Additionally, leukemic MCL exhibited frequent IGVH mutation (64\% versus $21 \%$; $P=.009)$ with preferential VH4-39 use ( $36 \%$ versus $4 \% ; P=.005)$ and followed a more indolent clinical course. Blastoid variants, increased number of genomic gains, and deletions of P16/INK4a and TP53 genes correlated with poorer out- comes, while 1p21 loss was associated with prolonged survival $(P=.02)$. In multivariate analysis, deletion of 9q21-q22 was the strongest predictor for inferior survival (hazard ratio [HR], 6; confidence interval [Cl], 2.3 to 15.7). Our study highlights the genomic profile as a predictor for clinical outcome and suggests that "genome scanning" of chromosomes 1p21, 9q21-q22, 9p21.3-P16/INK4a, and 17p13.1-TP53 may be clinically useful in MCL. (Blood. 2005;105:4445-4454)

() 2005 by The American Society of Hematology

\section{Introduction}

Mantle-cell lymphoma (MCL) is a distinct subtype of B-cell non-Hodgkin lymphoma (B-NHL) characterized by the translocation $\mathrm{t}(11 ; 14)(\mathrm{q} 13 ; \mathrm{q} 32)$ that leads to overexpression of cyclin D1. ${ }^{1,2}$ However, experimental evidence indicates that cyclin D1 activation may not be sufficient to induce malignant transformation, requiring concurrent deregulated expression of other dominant oncogenes and loss of tumor suppressor gene functions for lymphoma development. ${ }^{3}$ The portrait of genomic aberrations in addition to $\mathrm{t}(11 ; 14)(\mathrm{q} 13 ; \mathrm{q} 32)$ has been extensively characterized using conventional cytogenetic and comparative genomic hybridization $(\mathrm{CGH})$ methods. ${ }^{4-9}$ More recently, matrix CGH to dedicated DNA microarrays with 812 selected bacterial artificial chromosome (BAC) or P1-artificial chromosome (PAC) clones has described a typical pattern of genomic imbalances in MCL, revealing a higher number of aberrations than in previous $\mathrm{CGH}$ studies. ${ }^{10}$ Two additional reports have used CGH to BAC microarrays to delineate with high accuracy previously known as well as novel regions of DNA copy number increase and decrease in MCL genomes. ${ }^{11,12}$ It is remarkable that

From the Department of Hematology and Medical Oncology, Hospital Clínico, University of Valencia, Spain; Division of Oncology, Center for Applied Medical Research CIMA, University of Navarra, Pamplona, Spain; Institute of Human Genetics, University Hospital Schleswig-Holstein, Campus Kiel, Germany; Molecular Pathology Program, Centro Nacional de Investigaciones Oncolgógicas (CNIO), Madrid, Spain; Medical Research Council (MRC) Toxicology Unit, University of Leicester, United Kingdom; and Cancer Research Institute, University of California San Francisco, CA.

Submitted October 21, 2004; accepted January 14, 2005. Prepublished online as Blood First Edition Paper, February 17, 2005; DOI 10.1182/blood-2004-103907.

Supported by grants from Spanish Ministries of Health and Science and Technology, International Union Against Cancer (UICC), European Commis-
MCL shares several genomic gains and losses with other B-cell malignancies. ${ }^{4-10,13,14}$ However, the comparative high-resolution genomic analysis between MCL and other B-NHL subtypes has not yet been addressed. The repertoire of genomic imbalances is correlated with the lymphoma phenotype and survival in patients with MCL. The most typical examples are the deletions of TP53 and P16/INK4a genes, both associated with aggressive MCL. ${ }^{15-18}$ Using CGH, Bea et al reported that blastoid variants show an increased number of changes with respect to tumors with typical pathologic appearance. ${ }^{5}$ In another report, trisomies of $3 \mathrm{q}$ and $8 \mathrm{q}$ were observed in MCL with unmutated $I G V H$ genes whereas trisomy of $12 \mathrm{q}$ was more common in cases with mutated phenotype. ${ }^{19}$ In our previous CGH study, patients with leukemic MCL presented typically the deletion of chromosome 8 p. $^{7}$ The $8 \mathrm{p}$ loss was subsequently classified as a common change in MCL, $8,10,19,20$ but the association with leukemic disease was not clarified. More recently, Orchard et $\mathrm{al}^{21}$ reported that a subset of MCL displays mutated $I G V H$ genes and includes patients with good prognosis and nonnodal leukemic disease.

sion (Sixth Framework Programme for Research), Lymphoma Research Foundation (New York, NY) and the UTE-CIMA project.

F.R.-M. and J.C. contributed equally to this study.

The online version of the article contains a data supplement.

Reprints: Jose A. Martinez-Climent, Division of Oncology, Laboratory of Molecular Oncology, Center for Applied Medical Research CIMA, University of Navarra, Avda Pio XII, 55. 31008 Pamplona, Spain; e-mail: jamcliment@ unav.es.

The publication costs of this article were defrayed in part by page charge payment. Therefore, and solely to indicate this fact, this article is hereby marked "advertisement" in accordance with 18 U.S.C. section 1734.

(C) 2005 by The American Society of Hematology 
The definition of genetic differences among patients with MCL with diverse clinical features and outcomes should improve lymphoma classification, help in outcome prediction, and facilitate selection of treatment.

In the present study, we determined the pattern of genomic imbalances in a series of 68 patients with MCL and 45 B-cell lymphoma cell lines using CGH to a microarray with about 2400 BAC and PAC clones over the genome. ${ }^{22}$ Our study provides an example on how genome scanning of tumor cells using array-based CGH methods may be clinically useful in MCL as well as may implicate novel oncogene and suppressor gene loci in the pathogenesis of this lymphoma.

\section{Patients, materials, and methods}

\section{Subjects of study}

This is a retrospective study. We included samples obtained from 68 patients newly diagnosed with MCL. These comprised 58 cases from a previously published series ${ }^{23}$ as well as 10 additional cases. All tumors fulfilled World Health Organization (WHO) diagnostic criteria for MCL, including the demonstration of cyclin D1 overexpression, the $\mathrm{t}(11 ; 14)(\mathrm{q} 13$; q32) cytogenetically, and/or CCND1-IGH gene rearrangement by fluorescence in situ hybridization (FISH) or polymerase chain reaction (PCR). ${ }^{2}$ Genomic DNA was extracted from frozen tissue blocks (44 cases), bone marrow (BM) (6 cases), and peripheral blood (PB) (18 cases). Rearranged $I G V H$ genes were amplified using a seminested PCR method, as described previously. ${ }^{23}$ Clinical features of the patients are summarized in Table 1. Fifty-seven cases had lymph node involvement at diagnosis, whereas 11 cases were classified as nonnodal leukemic MCL on the basis of the absence at diagnosis of lymph node enlargement according to physical examination and computed tomography (CT) scan. Patients were treated with different chemotherapy schemes (58 cases), splenectomy (3 cases), and gastrointestinal resection ( 1 case), whereas 5 patients received no therapy; in 1 case, no clinical information was available. Complete remission was achieved in 22 cases, whereas 15 had partial response. This study was approved by the institutional review board of the Hospital Clinico University of Valencia. Patients were provided with informed consent, per Declaration of Helsinki.

\section{Cell lines}

A panel of 45 cell lines ( 9 MCL derived and 36 derived from patients comprising most other subtypes of B-cell malignancies) were studied: Granta 519, HBL-2, SP-49, Z-138, REC-1, NCEB-1, JVM-2, UPN-1, and UPN-2 (MCL); OZ, VAL, Karpas 422, DOHH-2, Karpas 353, PR-1, OCI-LY8, Karpas 231, SU-DHL6, ROS-50, RL, SCI-1, and Granta 452 (diffuse large B-cell lymphoma with $\mathrm{t}(14 ; 18)(\mathrm{q} 32 ; \mathrm{q} 21)$ ); BEVA, CTB-1, MD-901, MD-903, RIVA, RCK-8, and CIPULLO (diffuse large B-cell lymphoma lacking $\mathrm{t}(14 ; 18)$ ); ELIJAH, NAB-2, PL-29018, SERAPHINA, Wien-133, P-32, BALM-9, BL-41, CA-46, Namalwa, and KHM-10B (Burkitt lymphoma); SSK-41 and Karpas 1718 (marginal zone lymphoma); Karpas 1106 (primary mediastinal B-cell lymphoma); JVM-13 (B-cell prolymphocytic leukemia); and GASH (hairy cell leukemia). References for the derivation of the cell lines are summarized on Supplemental Table S1 (at the Blood website, see the Supplemental Tables link at the top of the online article).

\section{Microarray-based comparative genomic hybridization (array CGH)}

Genome-wide analysis of DNA copy number changes of 113 samples (68 patients and 45 cell lines) was performed using array CGH on a microchip with about $2460 \mathrm{BAC}$ and P1 clones in triplicate University of California San Francisco ([UCSF] Hum Array 2.0) with a resolution of 1.4 Mb across the genome. ${ }^{22}$ Methods and analytic procedures have been described elsewhere in detail. ${ }^{24,25}$ Briefly, $0.2 \mu \mathrm{g}$ test (tumor) and reference genomic DNAs were labeled by random priming using cyanine 3 (Cy3) and Cy5, respectively. After 48 hours of hybridization, slides were washed and mounted with DAPI (4,6 diamidino-2-phenylindole). The images of the arrays were captured using a charge-coupled device (CCD) camera, and the

Table 1. Clinical description of 68 patients with MCL: comparison of nodal versus nonnodal leukemic MCL

\begin{tabular}{|c|c|c|c|c|}
\hline & Patients with MCL & Nodal group & Leukemic group & $P$ \\
\hline \multicolumn{5}{|l|}{ Patients } \\
\hline No. & 68 & 57 & 11 & NA \\
\hline Male; female & $49 ; 19$ & $42 ; 15$ & $7 ; 4$ & NS \\
\hline Median age, y (range) & $70(46-86)$ & $69(46-86)$ & $74(49-77)$ & NS \\
\hline \multicolumn{5}{|l|}{ Clinical features } \\
\hline PB disease (\%) & $28(41)$ & $17(30)$ & $11(100)$ & $<.001$ \\
\hline BM infiltration (\%) & $40(60)$ & $29(52)$ & $11(100)$ & .002 \\
\hline Splenomegaly (\%) & $29(43)$ & $25(45)$ & $4(36)$ & NS \\
\hline Waldeyer ring (\%) & $5(7)$ & $5(9)$ & $0(0)$ & NS \\
\hline Gl tract (\%) & $9(13)$ & $9(16)$ & $0(0)$ & NS \\
\hline IPI 4 to $5(\%)$ & $8(12)$ & $8(14)$ & $0(0)$ & NS \\
\hline IgVH mutation (\%) & $19(28)$ & $12(21)$ & $7(64)$ & .009 \\
\hline \multicolumn{5}{|l|}{ IgVH family } \\
\hline VH3-23 (\%) & $5(7)$ & $4(7)$ & $1(9)$ & NS \\
\hline VH3-21 (\%) & $7(10)$ & $7(13)$ & $0(0)$ & NS \\
\hline VH3-34 (\%) & $9(13)$ & $8(14)$ & 1 (9) & NS \\
\hline VH3-59 (\%) & $8(12)$ & $6(11)$ & $2(18)$ & NS \\
\hline VH4-39 (\%) & $6(9)$ & $2(4)$ & $4(36)$ & .005 \\
\hline \multicolumn{5}{|l|}{ Cytology } \\
\hline Blastoid (\%) & $11(16)$ & $11(20)$ & $0(0)$ & NS \\
\hline Classic (\%) & $57(84)$ & $46(81)$ & $11(100)$ & NA \\
\hline IPI 4 to $5(\%)$ & $8(12)$ & $8(14)$ & $0(0)$ & NS \\
\hline Median survival, mo & 39 & 18 & 42 & NA \\
\hline Survival more than $36 \mathrm{mo}(\%)$ & $22(33)$ & $15(27)$ & $7(64)$ & .02 \\
\hline \multicolumn{5}{|l|}{ Genomic imbalances } \\
\hline $\operatorname{del}(8)(p 21.3)(\%)$ & $17(25)$ & $11(19)$ & $6(55)$ & .01 \\
\hline gain 8q24-MYC (\%) & $13(19)$ & $8(14)$ & $5(46)$ & .015 \\
\hline
\end{tabular}

GI indicates gastrointestinal; IPI, International Prognostic Index; NS, not significant; NA, not applicable. 
"UCSF SPOT" software was used to analyze the images. A second program, "SPROC," was used to associate clones with each spot and a mapping information file that allows the data to be plotted relative to the position of the BACs on the draft human genome sequence (http://genome. cse.ucsc.edu/cgi-bin/hgGateway?clade $=$ vertebrate \&org $=$ Human $\& \mathrm{db}=$ hg16\&hgsid=39217703; July 2003 freeze). A formal data filtering procedure was then performed, and a SPROC output file consisting of averaged ratios of the triplicate spots for each clone, standard deviations of the replicates, and plotting positions for each clone on the array was obtained. For visualization of genomic data, the TreeView program 1.60 (Stanford, CA) was used. The complete genomic data set from patients and cell lines with MCL is available in Supplemental Table S2.

\section{Data analysis}

Mean $\log _{2}$ ratios (tumoral DNA versus control DNA) were plotted, and the resultant graphs were converted to the $\log _{2}$ domain. The observed $\log _{2}$ ratios were excluded from further analysis if there were fewer than 2 replicate spots (out of 3 ) or if the standard deviation of the replicates was above 0.02 . The clones that were present in less than $50 \%$ of the samples were also removed from the dataset. The following mean $\log _{2}$ ratios (tumoral DNA versus control DNA) were used to classify genomic aberrations: genomic gain (between 0.39 and 0.95 ), genomic amplification (more than 0.95 ), or genomic loss (lower than -0.5 for hemizygosity and lower than -1.4 for homozygous deletion).

Statistically significant correlations between the genomic imbalances and clinical-pathological parameters were analyzed using the Fisher exact test for categorical parameters and the Mann-Whitney U test for continuous parameters. Because of the large number of clinical and biologic variables analyzed in relation to genomic changes, the significance of these associations was assessed using the false discovery rate test (FDRalgo; http:// www.math.tau.ac.il/ roee/meth.htm) ${ }^{26}$ Overall survival (OS) for each variable was calculated according to the Kaplan-Meier survival curves and $P$ values with the log-rank test. Multivariate analysis using the Cox regression model was performed only with the variables with a $P$ value less than .05 in the univariate analyses; only one BAC for each abnormal region was included for the multivariate analysis. Finally, to evaluate the possible relationship between OS and the total number of genomic gains and losses, we used the Cox proportional hazard model. The analyses were carried out using SPSS software for Windows. For delineation of common region of genomic imbalance in the lymphoma genomes, the position of the $\mathrm{BACs} / \mathrm{PACs}$ on the draft human genome sequence according to the May 2004 freeze was used (http://genome.cse.ucsc.edu/cgi-bin/hgGateway? clade $=$ vertebrate $\&$ org $=$ Human $\& d b=$ hg $17 \&$ hgsid $=39217703)$.

\section{Fluorescence in situ hybridization (FISH) analysis}

To confirm the array CGH results, FISH analysis using individual probes was performed on fixed cells from selected cell line strains and patient specimens using reported methods. ${ }^{7}$ The gene loci examined corresponded to overrepresented regions (CCND1, BCL2, MYC, and BCL6) and deleted segments (P16-INK4a, TP53, and ATM genes and the 13q14-D13S19 locus). In addition, BACs RP11-89M8, RP11-204M16, and RP11-110I16 (8p21.3 at TRAIL-DR5 locus); RP11-165N12, RP11-100A3, and RP1186C3 (13q31.3); RP11-155A5, RP11-111D18, RP11-513O11, RP11671P4, RP11-357N12, RP11-97N5, and RP5-1014O16 (at the Xq27-q28 amplicon); RP11-625P19 and RP11-938A5 (which flank the BMI1 locus); RP11-265K5 and RP11-675F6 (8p11.2 at FGFR1 locus); and recently described probes for the $J A K 2$ locus at 9p24 were also used for FISH studies. ${ }^{27}$ These clones were purchased from Research Genetics (Huntsville, AL), Vysis (Downers Grove, IL), or German Resource Center (Berlin, Germany).

\section{Multicolor FICTION}

Combined immunophenotyping and interphase FISH was applied in case MCL114 in a multicolor fashion (multicolor FICTION [fluorescence immunophenotyping and interphase cytogenetics as a tool for the investigation of neoplasms] technique) following the reported protocol $^{28}$ for the simultaneous detection of CCND1 (11q13) chromosomal breakpoints, BMI1 (10p12, clone RP11-938A5) amplification, and expression of proliferation marker Ki-67. Clones flanking the CCND1 locus (RP11-378E8/RP11211G23 and RP11-300I6/RP11-626H12) were labeled with Spectrum Orange (Vysis) and diethyl aminomethyl coumarin (DEAC), respectively. Clone RP11-938A5 was labeled with Spectrum Green (Vysis), and the primary antibody to Ki-67 (clone MIB-1; Dako Cytomation, Hamburg, Germany) was detected with a secondary antibody with Alexa-594 (Molecular Probes, Leiden, The Netherlands).

\section{Results}

\section{Genome scanning of lymphoma genomes with high-resolution array CGH}

To define with high resolution the genomic profile of MCL cells, we scanned 68 primary MCL samples and 9 derived MCL cell lines using array CGH with a microchip that includes 2460 BAC and
Figure 1. Array CGH profile of MCL. (A, left) Array CGH profile of MCL and other B-NHL subtypes. Patients with MCL are ordered from left to right according to the length of OS time, ranging from 0 to 115 months. FCL indicates follicle center lymphoma; BL, Burkitt lymphoma; DLBCL, diffuse large B-cell lymphoma; MZL, marginal zone lymphoma. (Right) Genomic delineation of the deletions of 1p21.2-p21.3 and of 10p14 with amplification of 10p12 (BMI1 gene locus). Genomic gains are shown in red, genomic losses in green, and regions with normal DNA copy number in black. (B) Multicolor FICTION analysis of case no. MCL114. BMI1 amplification was more common in apparently proliferating cyclin D1-positive MCL cells (38 of 50 cells; $76 \%$ ) as adjudged by Ki-67 staining, whereas those cyclin D1-positive cells negative for Ki-67 showed this gene amplification less commonly (14 of 50 cells; 28\%). A Zeiss Axioskop 2 fluorescence microscope (Zeiss, Gottingen, Germany) equipped with appropriate filter sets was used.

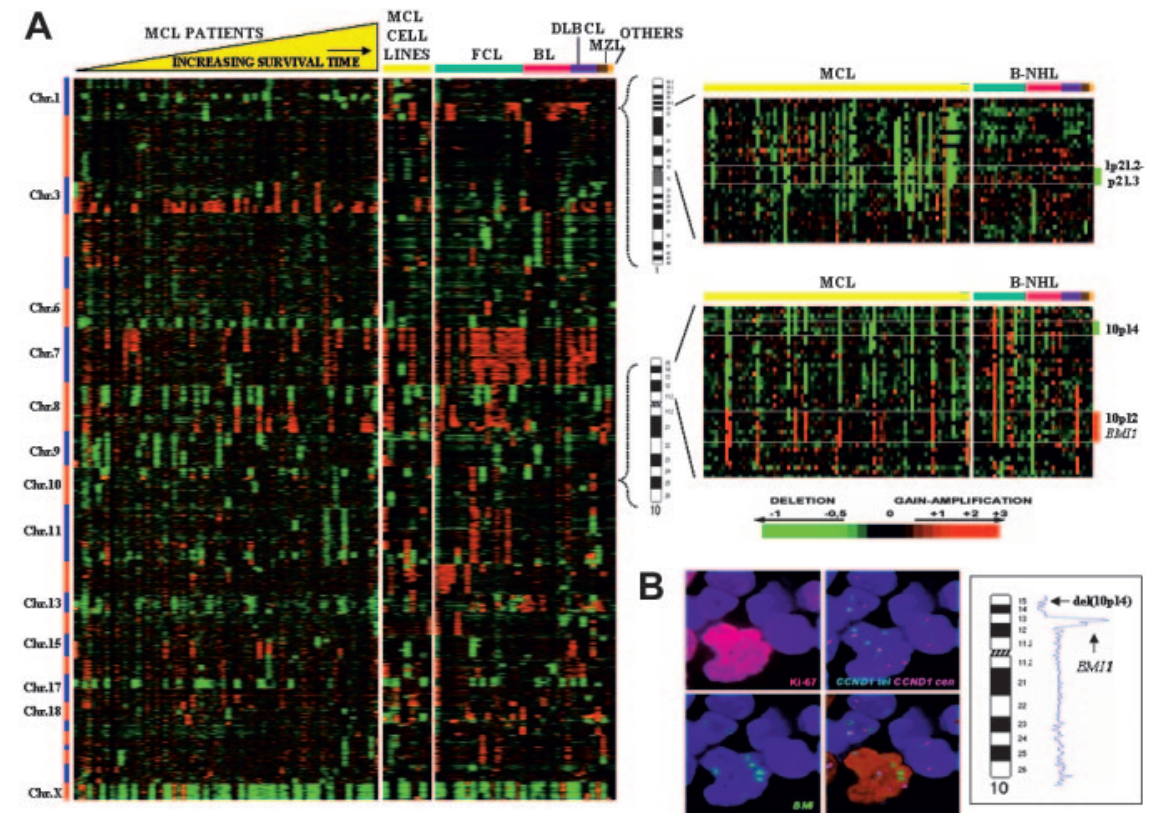


PAC clones spanning the genome (Figure 1A). As an initial comparison, we also profiled 36 cell lines derived from other B-NHL subtypes. To assess the sensitivity of the technique, the array $\mathrm{CGH}$ patterns were compared with previous conventional CGH of 22 patients with MCL and 7 MCL cell lines. ${ }^{7}$ On average, each of these tumors displayed 8 changes in conventional CGH (range, 0 to 22), including 4.4 genomic gains and 3.6 losses, whereas in array $\mathrm{CGH}$ analysis the number of altered regions was 14 per tumor (range, 0 to 35), including 7.5 gains and 6.5 losses. On average, array $\mathrm{CGH}$ detected in each sample 8 new genomic abnormalities that were undetected in conventional analysis and excluded, on average, 2 false $\mathrm{CGH}$ abnormalities, most of which corresponded to the telomeric chromosome regions. The mean number of clones that were altered on each patient sample was 159 (7.9\% of all efficiently hybridized clones), corresponding to 66 gains $(3.3 \%)$ and 93 losses $(4.6 \%)$. In the 9 MCL cell lines, there was an increased number of abnormal clones with respect to primary tumors (305 clones; $15.5 \%$ ), based on the higher number of gains (221 clones; $11 \%$ ), but a similar number of losses were seen (84 clones; $4.5 \%$ ). The remaining B-NHL cell lines showed higher number of changes, corresponding to 392 abnormal clones (18.9\%) with 231 gains (11\%) and 161 losses (7.9\%). To evaluate reproducibility of array CGH experiments, SCI1, PR1, OCI-Ly8, and Z138 cell lines and patient no. MCL045 were analyzed twice. In the comparative analysis, 13 clone pairs from the paired tumors (0.6\%; range, $4 \%-33 \%)$ from the different array CGH experiments showed discordant values (defined as differences in $\log _{2}$ value exceeding 0.3). We also used FISH to evaluate specific genomic alterations in selected tumors: 135 of the 140 FISH experiments (96.4\%) confirmed the DNA copy number changes of array CGH experiments. The detailed validation array CGH and FISH experiments are shown in Supplemental Table S3. In summary, array $\mathrm{CGH}$ was more sensitive than conventional CGH and was a highly reproducible method for the scanning of lymphoma genomes.

\section{Delineation of critical regions of recurrent genomic aberration in MCL}

Array CGH analysis identified a typical pattern of genomic changes in MCL (Figure 2). By overlapping the segments showing $\mathrm{BAC}$ and PAC clone variation in the different samples, we delineated the minimal regions of common amplification, low-level gain, and loss as shown in Table 2.

Amplifications and gains. Forty-eight amplification events (defined as the gain of more than 2 copies of DNA) targeting 25 different loci were identified. Amplification levels ranged from 3-fold to 7-fold. Amplicons included genes previously identified as being either amplified or overexpressed in MCL: CCND1 at $11 \mathrm{q} 13.3$ (observed in $1 \mathrm{MCL}$ primary sample and 2 cell lines), BCL6 in 3q27.3 (2 primary MCLs), BCL2 in 18q21.3 (3 MCL cell lines), $C D K 4$ in 12q14.1 (1 MCL cell line), and GPC5 in 13q31.3 (1 MCL primary tumor and 1 cell line) (Figure 3A). ${ }^{1,4,6-8,29,30}$ One of the most frequent amplified sites, observed in 8 of $68(12 \%)$ MCL primary samples and in 1 of $9(11 \%)$ MCL cell lines, was chromosome band 10p12.2, involving a critical segment that spanned the BAC clones RP11-200C22 and RP11-75N18. The recurrent peak of amplification was delineated to clone RP11$73 \mathrm{E} 18$, which contains the $B M I 1$ gene locus. ${ }^{30}$ To validate the array CGH data, clones RP11-625P19 and RP11-938A5, which are not included into the array and flank the BMII locus, were shown by FISH to be both amplified. In one specimen (case no. MCL114), BMII amplification was more common in apparently proliferating cyclin D1-positive MCL cells (38 of 50 cells; 76\%) as adjudged by

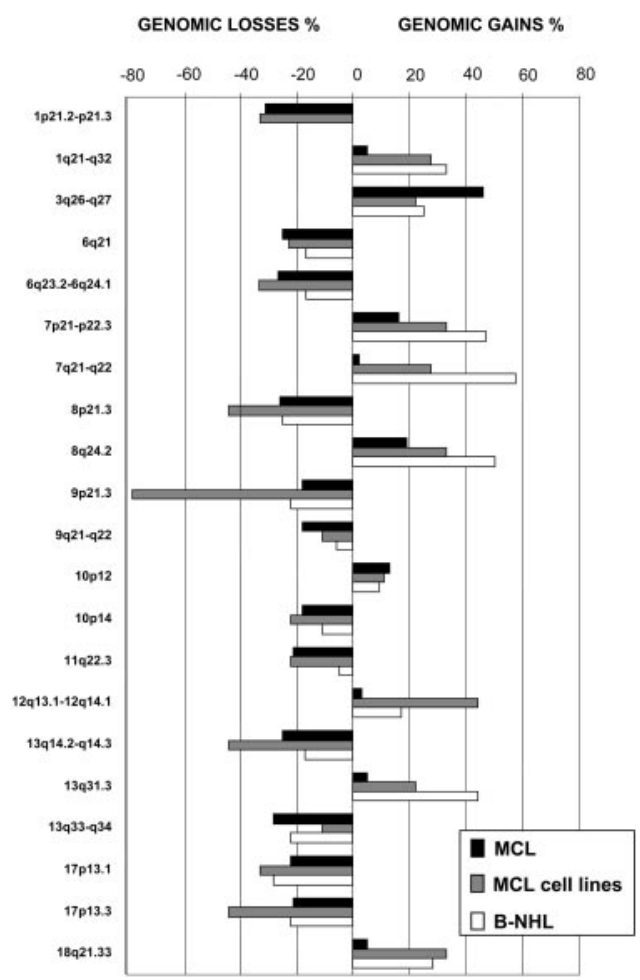

Figure 2. Genomic alterations in 68 patients with MCL, 9 MCL cell lines, and the other 36 B-NHL cell lines.

Ki-67 staining, whereas those cyclin D1-positive cells negative for Ki-67 showed this gene amplification less commonly (14 of 50 cells; 28\%) (Figure 1B). In contrast with other published reports, BMI1 amplification was not only observed in cases without P16-INK $4 a$ deletion, as both alterations were coincident in 3 tumors. ${ }^{30,31}$ The 10p12.2 amplicon also contained the phosphatidylinositol-4-phosphatase 5-kinase PIP5K2A gene, a regulator of cell proliferation, mapped to less than $200 \mathrm{~kb}$ from BMI1. Additional amplified loci in MCL cells were previously reported as being the target of amplification in other B-NHL subgroups, such as the chromosome band 1q21-q22 and JAK2 in 9p24.1, which was amplified in the MCL cell line Z138 and in 2 patients with MCL. In addition, other amplified oncogenes not previously implicated in the pathogenesis of B-NHL were seen: FGFR1 in 8p11.2 (showing amplification in 1 MCL primary sample and single copy gain in 6 additional samples) and JUNB in 19p13.2 (1 MCL sample). FISH analysis confirmed amplification of JAK2 and FGFR1 genes in the corresponding amplified tumor specimens. Novel regions of genomic amplification involved chromosomes 1p36.1, 1p33-p34, 4p12, 4q34-q35, 6q23, 11p14, 11q25, 13q34, 14q32.3, 18p11.21, 20p11.2, and 22q13.2 (each was observed in only 1 sample; complete array CGH data are shown in Supplemental Table S2). Besides, a novel amplicon from BAC RP4-809E13 at Xq26.3 to the telomere, spanning the fragile mental retardation 1 and 2 gene loci, was also confirmed in UPN1 cell line and in 2 primary tumors using FISH. In addition to amplicons, the most common region of low-level copy gain was the long arm of chromosome 3 (3q), which was observed in 31 of $68(46 \%)$ MCL primary samples and in 2 of the 9 MCL cell lines (22\%). By aligning the common BACs with DNA copy number increase, the critical segment of genomic gain spanned BAC RP11-172G5 in 3q26.3, containing the ECT2 oncogene, which was also amplified in 2 cases. Other frequent sites of single copy gain involved large chromosomes segments at 
From bloodjournal.hematologylibrary.org at NAVARRA UNIV on May 11, 2011. For personal use only.

Table 2. High-resolution delineation of common regions of gain, amplification, and loss in MCL and in other B-NHL subtypes

\begin{tabular}{|c|c|c|c|c|c|c|c|c|c|}
\hline & $\begin{array}{l}\text { Patients with MCL; } \\
\qquad n=68\end{array}$ & $\%$ & $\begin{array}{c}\text { MCL cell lines; } \\
n=9\end{array}$ & $\%$ & $\begin{array}{l}\text { B-NHL cell lines; } \\
\quad n=36\end{array}$ & $\%$ & Consensus region & Size, Mb & Candidate genes \\
\hline \multicolumn{10}{|c|}{ Gain (amplification*) } \\
\hline $3 q 26.3$ & $31(2)$ & 46 & 2 & 22 & 9 & 25 & GS-115H3-RP11-114M1 & 5.8 & ECT2 \\
\hline 7p21.1-p22.3 & 11 & 16 & 3 & 33 & 17 & 47 & CTC-329F6-RP11-71F18 & 17 & CARD11, ETV1 \\
\hline $8 \mathrm{p} 11.2$ & $6(1)$ & 9 & 1 & 11 & 5 & 14 & RP11-100B16-RP11-284J3 & 2.5 & FGFR1 \\
\hline $8 q 24.2$ & 13 & 19 & 3 & 33 & $18(2)$ & 50 & RP11-65D17-RP11-237F24 & 1.5 & MYC \\
\hline $9 p 24.1$ & $2(2)$ & 3 & $1(1)$ & 11 & 4 & 11 & RP11-125K10-RP11-165014 & 1.3 & JAK2 \\
\hline 10p12.2 & $8(3)$ & 12 & 1 & 11 & 3 & 8 & RP11-200C22-RP11-75N18 & 2.5 & BMI1, PIP5K2A \\
\hline $11 q 13.3$ & $7(1)$ & 9 & $2(1)$ & 22 & 3 & 8 & CTB-36F16-RP11-120P20 & 0.8 & $B C L 1$ \\
\hline $12 q 13.1-q 14.1$ & 2 & 3 & $4(1)$ & 44 & 6 & 17 & RP11-132H4-RP11-276L24 & 6 & CDK4 \\
\hline $13 q 31.3$ & $3(1)$ & 5 & $2(1)$ & 22 & $16(6)$ & 44 & $\mathrm{RP} 11-86 \mathrm{C} 3$ & 1 & GPC5, miRNAs \\
\hline 15q22.3-q25.1 & 6 & 9 & - & 0 & $2(1)$ & 6 & RP11-60J12-RP11-30M4 & 15 & $P M L$ \\
\hline $18 q 21.33$ & 3 & 5 & $3(3)$ & 33 & $10(4)$ & 28 & RP11-40D15-RP11-75O12 & 2.8 & $B C L-2$ \\
\hline Xq27.3-q28 & 4 & 6 & $2(1)$ & 22 & 4 & 11 & CTD-2060E7-RP11-221G13 & 2 & FMR1, FMR2 \\
\hline \multicolumn{10}{|l|}{ Genomic loss } \\
\hline $1 \mathrm{p} 21.2-\mathrm{p} 21.3$ & 21 & 31 & 3 & 33 & - & 0 & RP11-156M23-RP11-178M11 & 5.6 & CDC14A, miRNA-137 \\
\hline $6 \mathrm{q} 21$ & 17 & 25 & 2 & 22 & 6 & 17 & RP11-165E15-RP11-59F18 & 5 & FOXO3A, SESN1 \\
\hline $6 q 23.2-q 24.1$ & 18 & 26 & 3 & 33 & 6 & 17 & RP11-177M4-RP11-15H7 & 6.8 & IFNGR1 \\
\hline $8 p 21.3$ & 18 & 26 & 4 & 44 & 9 & 25 & RP11-274M9-RP11-89M8 & 1.5 & $D R 4, D R 5, D c R 1, D c R 2$ \\
\hline $8 p 23.3$ & 20 & 29 & 3 & 33 & 8 & 22 & GS1-77L23-RP11-240A17 & 1.6 & DLGAP2, FBOXO25 \\
\hline $9 p 21.3$ & 12 & 18 & 7 & 78 & 8 & 22 & CTB-65D18-RP11-33O15 & 3 & P16-INK4A \\
\hline $9 q 21.33-q 22.33$ & 12 & 18 & 1 & 11 & 2 & 6 & RP11-65C15-RP11-147H22 & 13 & CDC14B, FANCC \\
\hline 10p14 & 12 & 18 & 2 & 22 & 4 & 11 & RP11-5B23-RP11-72C6 & 1.4 & $P R K C Q, K I N$ \\
\hline $11 \mathrm{q} 22.3$ & 14 & 21 & 2 & 22 & 1 & 3 & RP11-179B7-RP11-964M3 & 4 & ATM \\
\hline $11 \mathrm{q} 25$ & 2 & 5 & 2 & 22 & 8 & 22 & RP11-17M17-RP11-27H17 & 1.5 & OPMCL, THY28 \\
\hline $13 q 14.2-q 14.3$ & 17 & 25 & 4 & 44 & 6 & 17 & RP11-52B21-RP11-16F6 & 6 & miRNA15, miRNA16 \\
\hline $13 q 33.3-q 34$ & 19 & 28 & 1 & 11 & 6 & 22 & RP11-183A20-RP11-61/17 & 1.4 & ING1, LIG4, TNFSF13B \\
\hline $17 p 13.1$ & 15 & 22 & 3 & 33 & 10 & 28 & RP11-61B20-RP11-9A21 & 1.4 & P53 \\
\hline $17 \mathrm{p} 13.3$ & 14 & 21 & 4 & 44 & 8 & 22 & GS1-68F18-RP11-26N16 & 1 & OVCA1, OVCA2, RPA1, CRK \\
\hline
\end{tabular}

*The number of tumors with amplification.

7p21.1-p22.3 (16\%), 8p11.2 at FGFR1 gene (9\%), 8q24.2 (including the $M Y C$ gene locus) (19\%), 11q13.3 around the CCDN1 gene (9\%), and 15q22.3-q25.1 (9\%).

Deletions. By alignment of abnormal BAC and PAC clones, the regions of genomic loss were narrowed down to minimal segments spanning the loci of tumor suppressor genes previously implicated in MCL pathogenesis but also delineated a number of previously unreported regions containing putative target genes. Fourteen MCL primary samples and 2 MCL cell lines showed deletion of 11q22.3 spanning the ATM gene locus. In addition, the UPN1 cell line presented deletion of a mole telomeric segment at 11q23.3-qter while exhibiting normal DNA copy number of the ATM locus, as assessed by FISH (data not shown). In 9p21.3, 12 primary samples and 7 of 9 cell lines exhibited deletion encompassing the P16-INK4a locus. In chromosome 6q, 2 independent segments of common deletion were delineated at $6 \mathrm{q} 21$ and 6q23.2-q24.1 (Table 2). Chromosome 13q was the most altered chromosome. Two different deletions were seen, the more frequent being delineated to $13 q 14.2-q 14.3$ in 17 primary samples $(25 \%)$ and in 4 of 9 cell lines (44\%). This interval was coincident with the common segment of loss in B-cell chronic lymphocytic leukemia (B-CLL). A second deletion was more telomeric and encompassed about $1.4 \mathrm{Mb}$ of genomic sequence at 13q33.3-q34, being identified in 19 primary samples and 1 cell line. The loss of 13q33-q34 was independent from the $13 \mathrm{q} 14$ deletion in 6 tumors and included the tumor suppressor gene ING1 and the gene implicated in DNA repair, LIG4, and TNFSF13B. Another common loss involved 1p21.2-1p21.3 and was observed in 21 primary MCL (31\%) and 3 MCL cell lines (33\%), being the critical segment delineated to an approximately 5.6 Mb segment between BACs RP11-156M23 and RP11-178M11. The deleted interval contained the cell division cycle 14A gene (CDC14A). Two different segments of loss at $8 \mathrm{p}$ were delineated: $8 \mathrm{p} 21.3$, present in $26 \%$ of MCL samples, spanning a critical region of $1.5 \mathrm{Mb}$ at the tumor necrosis factor-related apoptosis-inducing ligand (TRAIL) receptor gene cluster; and a more distal deletion of $1.6 \mathrm{Mb}$ in $8 \mathrm{p} 23.2$, involving a similar proportion of cases. The loss in the long arm of chromosome 9q, which was seen in $12 \mathrm{MCL}$ cases and $1 \mathrm{MCL}$ cell line, has not been previously reported in MCL. The critical interval of loss spanned $13 \mathrm{Mb}$ of genomic sequence between $9 \mathrm{q} 21.33$ to $9 \mathrm{q} 22.33$. This interval included as representative candidate suppressor genes the cell cycle regulator $C D C 14 B$ and the Fanconi anemia complementation group $C$ gene (FANCC). In 5 of the 12 tumors, the deletion of 9q21-q22 was not coincident with the loss of 9p21.3 whereas in the remaining 7 samples and in the NCEB1 cell line both 9p and 9q arms were deleted as a consequence of a monosomy of chromosome 9. Another frequent genomic loss was delineated to 10p14 in 12 primary samples and 2 MCL cell lines. This novel deletion was associated in 9 cases with BMII gene gain/amplification and was narrowed down to a segment of about $1.4 \mathrm{Mb}$ in size that included the candidate suppressor $P R K C Q$ encoding for a serine-threonine kinase. In chromosome $17 \mathrm{p}$, a critical segment of loss at $17 \mathrm{p} 13.1$ spanning TP53 gene locus was delineated in 15 primary MCL samples and 3 cell lines. In addition, a previously unreported locus of common deletion in $17 \mathrm{p} 13.3$ was delineated to less than $1 \mathrm{Mb}$ of genomic sequence in 14 MCL specimens and in 4 of the 9 MCL cell lines, harboring the RPAI (replication protein 1) and the OVCAI and $O V C A 2$ genes as putative targets. Four regions of homozygous deletion were observed, the most frequent being the loss of P16/INK $4 a$ locus (1 primary tumor and 4 cell lines). In addition, biallelic losses of 11q14-q23 containing the ATM gene, 11p12-p14, and Xp22.3 (spanning Kallmann syndrome locus), which was 


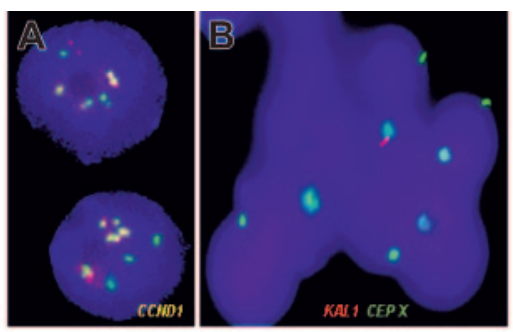

C
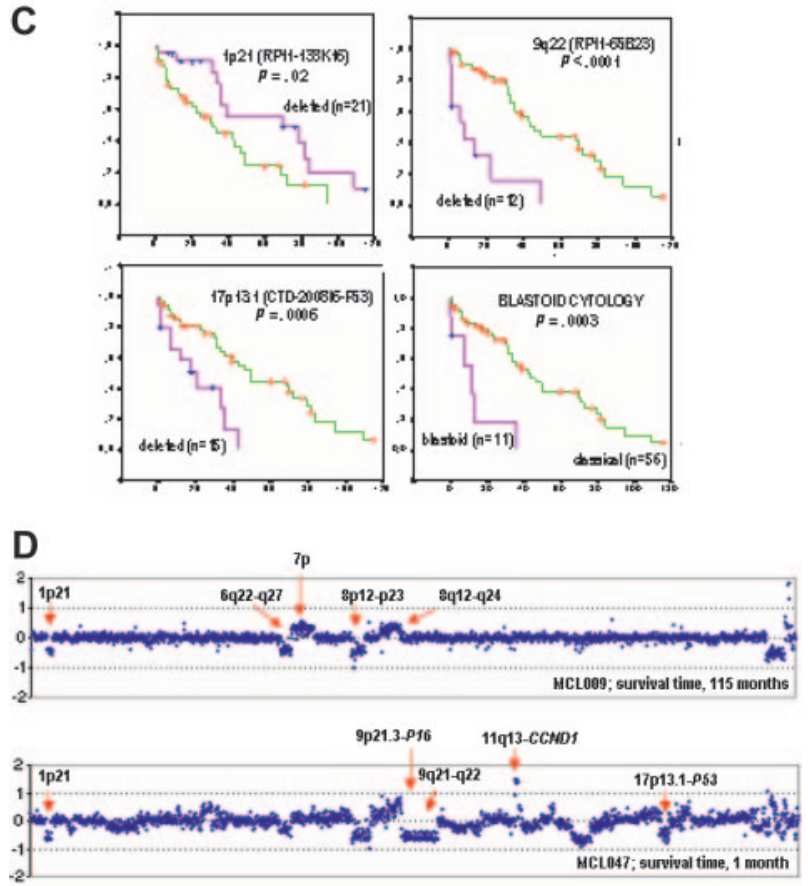

Figure 3. Genomic changes and survival in MCL. (A) FISH analysis using CCND1 flanking probes in patient MCL047 showing 11q13 amplification. (B) FISH analysis of patient MCL114 (male) showing homozygous deletion of the Kallmann syndrome locus. Green indicates centromeric probe for chromosome X; red, probe for KAL1 gene locus at Xp22.31, which is not detected in all but one of the interphase nuclei. A Zeiss Axioplan fluorescence microscope with Vysis imaging software was used. (C) Array CGH and survival in MCL. OS of patients with MCL according to the deletions of chromosomes p21, 9q21-q22, and 17p13.1 at TP53 and blastoid versus classical cytology. (D) Examples of array CGH profiles of 2 patient samples with MCL. (Top) Case no. MCL009 shows few genomic alterations, including deletions of 1p21, 6q22-q27, and 8p12-p23.3 and gains of 7p11-p22 and 8q12-q24. Survival time for this patient was 115 months since diagnosis. (Bottom) The array CGH profile of case no. MCL047 showing a large number of genomic changes, including deletions of 1p21 and 9p21.3 at P16/INK4a gene locus and 9q21-q22 and 17p13.1 at TP53 gene locus, along with high-level amplification within $B C L 1$ gene locus. Survival time for this patient was 1 month since diagnosis.

confirmed by FISH using a clone for $K A L$ gene, were seen in 3 separate primary MCL samples (Figure 3B).

\section{MCL genomic signature is different from other B-NHL subtypes}

To begin to perform the comparative genomic analysis between MCL and other B-NHL subtypes, we analyzed the array CGH results in these groups (Figure 2). Many of the genomic changes observed recurrently in MCL cells were also detected with similar frequencies in other B-NHL subtypes. The detailed high-resolution comparison also showed that the critical segments were coincident in MCL and other B-NHLs, such as the deletion of chromosomes 6q21, 6q23.2-q24.1, 8p21.3, 8p23.3, 9p21.3, 13q14.2-q14.3, $13 q 33.3-q 34$, and 17 p13.1 and the gain/amplification of chromosomes 7p21-p22 and 8q24 (Table 3). The gain of chromosome band 3 q26-q27 was observed in $46 \%$ of MCL samples but also in $25 \%$ of the other B-NHLs. Other aberrations were frequent in MCL but rarely detected in the other B-NHLs: the deletion of chromosome $1 \mathrm{p} 21$, observed in 24 of 77 MCLs but in none of the B-NHLs $(31 \%$ versus $0 \% ; P<.0001)$, and the deletions of $9 \mathrm{q} 21-\mathrm{q} 22$ (18\% versus $6 \% ; P=.005)$ and $11 \mathrm{q} 22.3$ at the ATM gene locus (21\% versus $3 \% ; P=.0001)$. Notably, coincident $10 \mathrm{p} 12$ amplification at $B M I 1$ locus and 10p14 deletion were also exclusively observed in 9 cases of MCL but not in any other B-NHL sample $(P<.0001)$. Besides, a number of other changes such as the gain and amplification of chromosomes 1q21-q31, 7q21-q22, 12q13, and 18q21 were observed in both MCL and B-NHL cell lines but not in the primary tumors, suggesting that these alterations are related to the cell line origination and culturing procedures. In summary, the array CGH scanning analysis identified an MCL genomic signature that included some gene loci that are rarely observed in other B-NHL cell lines.

\section{Association of DNA copy number variation with biologic and clinical features in MCL}

To begin to assess whether variation in genomic copy number as determined by array $\mathrm{CGH}$ might be associated with clinical or biologic parameters in MCL, and therefore might be of diagnostic and prognostic value, we correlated array CGH results with clinical and histologic parameters as well as with $I G V H$ mutational status (Table 1). Given the large number of possible associations between clinical-biologic parameters and genomic changes and the relative small number of patients included in the study, the univariate analyses should be interpreted with caution. There were differences between typical and blastoid tumors, such as the gain and amplification of 7p21.1-p22.3, 15q22.3-q25.1, and 13q31.3. However, abnormalities of P16/INK $4 a$ or TP53 genes were not associated with blastoid cytology. ${ }^{5,15-18}$ Seventy-two percent of MCL samples showed unmutated $I G V H$ genes, and this group presented frequent gains of $3 \mathrm{q} 26-\mathrm{q} 27$ and $15 \mathrm{q} 22-\mathrm{q} 25(P=.005)$. The presence of BM infiltration and/or PB dissemination was correlated with the deletion of $8 \mathrm{p} 21.3$, confirming our previous observation. ${ }^{7}$ Because of the large number of comparisons performed, the significance of associations was further assessed using an appropriate multiple-testing $P$ value adjustment procedure. After these adjustments, only 3 associations (gains of 13q31 and 15q21-q22 with blastoid cytology and deletion of 17p13.1 at TP53 gene with BM infiltration) remained statistically significant (Table 3).

\section{Leukemic MCL is a distinct clinical subgroup characterized by unique genomic and molecular features}

In our series, 57 cases had lymph node involvement at diagnosis whereas 11 cases were classified as leukemic MCL. These nonnodal cases had a similar clinical presentation with marked lymphocytosis $\left(8.8 \times 10^{9} / \mathrm{L}\right.$ to $\left.50 \times 10^{9} / \mathrm{L}\right)($ Table 4$)$. Patients with leukemic MCL showed a different genetic profile than the nodal cases, including (1) frequent deletion of $8 \mathrm{p} 21.3$ at the TRAIL receptor gene cluster (55\% versus $19 \% ; P=.01)$; (2) gain of $8 \mathrm{q} 24.1$ at $M Y C$ gene locus (46\% versus $14 \% ; P=.015$ ); and (3) frequent $I G V H$ gene mutation $(64 \%$ versus $21 \% ; P=.009)$ with preferential VH4-39 use (36\% versus $4 \% ; P=.005)$. In addition, a more indolent course was observed for the nonnodal group, being 7 of 11 patients (64\%) surviving for more than 3 years whereas only $27 \%$ of the patients in the nodal group experienced this long survival (median OS time, 42 versus 18 months; $P=.02$ ). Our data may indicate that nonnodal leukemic cases represent a distinct clinical subgroup of MCL with unique molecular and genetic 
From bloodjournal.hematologylibrary.org at NAVARRA UNIV on May 11, 2011. For personal use only.

Table 3. Association of genomic alterations and clinical and biologic features in patients with MCL

\begin{tabular}{|c|c|c|c|c|c|c|c|c|}
\hline & $\begin{array}{l}\text { Blastoid } \\
\text { cytology }\end{array}$ & $\begin{array}{c}\text { PB } \\
\text { dissemination }\end{array}$ & $\begin{array}{c}\text { BM } \\
\text { disease }\end{array}$ & $\begin{array}{l}\text { Splenic } \\
\text { disease }\end{array}$ & $\begin{array}{c}\operatorname{lgVH} \\
\text { mutation }\end{array}$ & VH3-23 & VH4-34 & VH4-59 \\
\hline \multicolumn{9}{|c|}{ Gain/amplification } \\
\hline $3 q 26-q 27$ & - & .005 & - & - & $.01^{*}$ & - & - & - \\
\hline 7p21-pte1 & .04 & $.04^{*}$ & - & - & - & - & - & - \\
\hline $8 q 24$ & - & - & - & - & - & - & - & .04 \\
\hline $13 q 31$ & $<.001 \dagger$ & - & - & - & - & - & - & - \\
\hline $15 q 21-22$ & $.002 \dagger$ & - & - & - & $.005^{\star}$ & - & - & - \\
\hline \multicolumn{9}{|c|}{ Genomic loss } \\
\hline $1 \mathrm{p} 21$ & - & - & .02 & - & - & - & - & - \\
\hline $6 q 22-q 23$ & - & - & - & - & - & - & .007 & - \\
\hline $8 p 21.3$ & - & .008 & .008 & - & - & - & - & - \\
\hline $9 p 21.3$ & - & - & - & - & - & .026 & - & - \\
\hline $9 q 21-q 22$ & - & - & - & - & - & - & - & - \\
\hline $11 \mathrm{q} 22.3$ & - & - & - & .03 & - & - & - & - \\
\hline $13 q 14.2$ & - & $.03^{*}$ & - & - & - & - & - & - \\
\hline $13 q 33-34$ & - & $.007^{\star}$ & - & - & - & - & - & - \\
\hline $17 \mathrm{p} 13.1$ & - & .01 & $.002 \dagger$ & - & - & - & - & - \\
\hline
\end{tabular}

Only statistically significant correlations $(P<.05)$ are shown.

*These values indicate inverse correlations: Tumors without PB dissemination showed gain of 7p21-pte1 and deletions of 13q14.2 and 13q33-q34; tumors without mutation showed gain of 3q26-q27 and 15q21-q22.

†After adjustments using the FDR test, only these associations remained statistically significant.

features that can be distinguished from the typical cases with lymph node involvement at diagnosis.

\section{Genomic changes may predict clinical outcome in patients with MCL}

The median OS for the patients in the series was 39 months (range, 0 to 115 months). In the univariate analysis, a number of clinical parameters correlated with negative differences in OS: blastoid versus typical histology (median OS, 11 versus 43 months; $P=.0003$ ) and spleen disease at diagnosis (median OS, 31 versus 49 months; $P=.01$ ). In addition, an increased number of genomic gains but not losses was associated with shorter OS $(P=.01)$. Individual genomic losses were also correlated with shorter survival: deletion of 9p21.3 at P16-INK4a locus (median OS, 13 versus 46 months; $P=.002$ ); deletion of $17 \mathrm{p} 13.1$ at $T P 53$ gene (median OS, 20 versus 49 months; $P=.0006$ ); and deletion of chromosome 9q21-q22 (median OS, 8 versus 46 months; $P<.0001$ ) (Figure 3C). In multivariate analysis, only the deletions of $9 \mathrm{q} 21$ q22 (hazard ratio [HR], 6.0; confidence interval [CI], 2.3 to 15.7) and of $17 \mathrm{p} 13.1$ including TP53 gene (relative risk [RR], 4.3; CI, 1.5 to 12.3 ) and splenic disease (RR, 4.8; CI, 1.2 to 15.4 ) were correlated with inferior survival probability. Only one parameter, the deletion of chromosome band $1 \mathrm{p} 21$, was correlated with longer OS (median OS, 70 versus 31 months; $P=.02$ ). Next we analyzed the genotypes of 14 patients with MCL who were alive for more than 5 years since diagnosis: Seven $(50 \%)$ had a deletion of $1 \mathrm{p} 21$, but none showed deletions of 9q21-q22, 9p21.3-P16/INK4a, or 17p13.1-TP53 (Figure 3D). These data indicate that the array CGH profile may be a strong predictor of survival in MCL, not only for the identification of patients with poor prognosis but also for the recognition of long-term survivors.

\section{Discussion}

Here, we report on an initial example of how genomic profiling of tumor cells using array-based CGH may be clinically useful in MCL. The microarray used included about 2460 BAC and PAC clones and was shown to be more sensitive for detection of either deletions or amplifications than conventional $\mathrm{CGH}$ and to be reproducible in cell lines and primary material. Using this technique, we delineated previously reported alterations but also identified novel regions of genomic imbalance in MCL. Previously, Kohlhammer et al $^{10}$ applied matrix CGH to MCL samples using a microchip containing 812 BAC clones, 513 of which were selected for chromosome regions previously known to be altered in MCL. In addition, 209 clones were linearly distributed across the genome at a distance of about $15 \mathrm{Mb}$, and 90 additional clones covered the sex chromosomes. Interestingly, these authors defined consensus regions of alteration, such as a 2.7 Mb amplicon at 10p12 that included the BMII gene, a deletion of $2.4 \mathrm{Mb}$ at $8 \mathrm{p} 21$ including the TRAIL receptor genes, a $6.9 \mathrm{Mb}$ deletion encompassing 13q34, and a deletion of $1.7 \mathrm{Mb}$ at 11q22-q23 encompassing the ATM locus. Our data can also be compared with the array CGH study of 14 patients with MCL by Schraders et al, where interesting genes such as KITLG (12q21), GPC5 (13q31), and ING1 (13q34) were identified as potential candidate targets of genomic aberration. ${ }^{12}$ The implication of the GPC5 gene locus in the 13q31.3 amplicon in MCL was previously reported. ${ }^{29}$ Using a similar BAC microarray approach that included 2348 clones over the genome, Tagawa et al analyzed 29 patients with MCL. ${ }^{11}$ They identified a common pattern of genomic imbalances that is very similar to that reported here, indicating that there are no significant geographic variations in MCL genomes. Notably, these authors identified homozygous deletion of $2 \mathrm{p} 11$ at IGK gene locus, confirming our previous observation. ${ }^{29}$ In addition, a novel homozygous deletion of the proapoptotic gene BIM in chromosome $2 \mathrm{q} 13$ was identified, suggesting the presence of a novel candidate tumor suppressor gene involved in apoptosis in MCL. ${ }^{32}$ Our array CGH method, which includes approximately one probe every $1.4 \mathrm{Mb}$ of genome sequence, narrowed down most of these previous alterations to smaller intervals. Moreover, the key biologic value of our powerful approach lay in its ability to detect small amplicons and deletions that were undetected in the previous publications. Notable examples are the novel deletions of 9q21-q22,10p14, and 17p13.3 and the gain/amplification of 
From bloodjournal.hematologylibrary.org at NAVARRA UNIV on May 11, 2011. For personal use only.

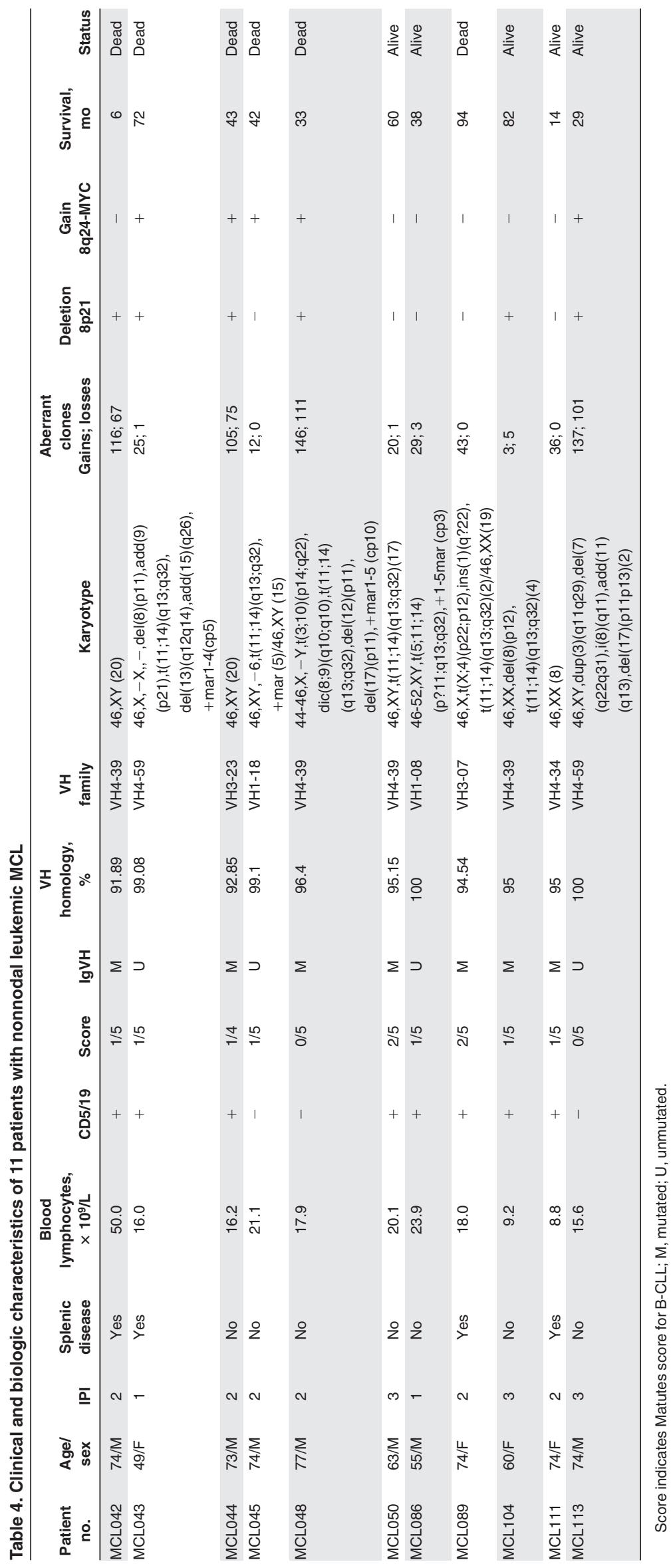


8p11.2 at FGFR1 locus, 9p24 involving JAK2 gene and Xq27-q28 encompassing FMR 1 and $F M R 2$ gene loci.

By comparing the genomes of MCL and different B-NHL cell lines, we defined a typical MCL genomic signature that included some genomic imbalances rarely observed in other B-NHL subgroups. Notably, however, we only compared MCL with cell lines established from patients with B-NHL, and these models may not be fully representative of the genotypes observed in primary tumors. One notable example was the deletion of $11 \mathrm{q} 22.3$ spanning the ATM gene locus, which was seen in $21 \%$ of MCL but rarely in other B-NHLs. ${ }^{33}$ In addition, the deletion of chromosome 1 p21 was exclusively observed in roughly one third of MCL samples but not in any other B-NHL cell line or in a varied B-NHL primary sample set (F.R.-M. and J.A.M.-C., unpublished data, January 2005). The consensus region of loss spanned about 5.6 Mb of genomic sequence at $1 \mathrm{p} 21.2-\mathrm{p} 21.3$ and included the candidate tumor suppressor $C D C 14 A$, which plays an essential role in controlling mammalian cell cycle progression and DNA replication and whose down-regulation causes chromosome defects into daughter cells. ${ }^{34}$ The deletion of 9q21-q22 was another alteration common in MCL but rare in other B-NHL genomes. In previous reports, this deletion has been found only occasionally. $4-10,12,19,20,29$ In the recent report by Tagawa et al, however, 13 of 29 patients with MCL showed similar deletion of $9 \mathrm{q} 22$; however, no clinical data were provided by the authors. The $9 \mathrm{q}$ deletion may be coincident with the loss of 9q13-q21 observed in acute myeloid leukemia, which seems to be also related to poor prognosis. ${ }^{35}$ The commonly deleted interval in MCL included some candidate suppressor genes such as the cell cycle regulator gene $C D C 14 B$ and the $F A N C C$ gene involved in DNA repair, apoptosis, and tumorigenesis. ${ }^{36}$ In our series, deletion of $9 q 21-q 22$ was the strongest independent factor associated with inferior survival, even when compared with classical poor prognostic parameters in MCL such as blastoid cytology and TP53 or P16-INK4a gene deletions. ${ }^{5,17,19,37}$ Further characterization of this novel genomic deletion to identify the putative target tumor suppressor gene(s) is currently in progress. We confirmed that regional alteration of chromosome $10 \mathrm{p}$ is frequent in MCL, indicating 2 different aberrations. The first one involving 10p12 was delineated to the $B M 1$ gene locus, which is a frequent target of amplification and overexpression in MCL. 5,10,30 The BMI1 gene is a putative oncogene of the Polycomb group that cooperates with $M Y C$ in the generation of lymphomas and that regulates the cell cycle by transcriptionally repressing P16-INK4a. ${ }^{38}$ However, the $10 \mathrm{p} 12$ amplicon also contains the PIP5K2A gene, mapped to less than $200 \mathrm{~kb}$ from $B M I 1$. This regulator of cell proliferation is highly expressed in the lymph nodes and may be another candidate target for the 10p12 amplification of MCL. In all 9 cases with 10 p12 gain/amplification, as well as in other $6 \mathrm{MCL}$ cases, deletion of $10 \mathrm{p} 14$ was observed. This novel site of loss was narrowed down to a segment of about $1.4 \mathrm{Mb}$ in size that included a candidate suppressor gene $P R K C Q$ encoding for the protein kinase $C$ theta form, a serine-threonine kinase required for T-cell receptor (TCR)-induced nuclear factor- $\kappa \mathrm{B}(\mathrm{NF}-\kappa \mathrm{B})$ activation. ${ }^{39}$ This deletion was also common in other B-NHLs, but its simultaneous presence with 10p12 amplification was exclusive of MCL. The investigation of the gene targeted by 10 p14 deletion and its putative association with BMI1 gene requires further investigation.

Several reports have suggested that nonnodal leukemic MCL may be a distinct form of the disease. ${ }^{21,40}$ Our data indicate that leukemic cases represent a clinical subgroup of MCL with unique molecular and genetic features that should be distinguished from the typical cases with lymph node involvement at diagnosis. The leukemic cases exhibited frequent $I G V H$ gene mutation and a more indolent clinical course than the nodal MCL. These data are in agreement with a recent publication by Orchard et al. ${ }^{21}$ In a previous report, we suggested that leukemic MCL was associated with the loss of chromosome 8p. ${ }^{7}$ Although $8 \mathrm{p}$ was subsequently identified as frequent deletion site in MCL, ${ }^{8,10,20,41,42}$ the association with leukemic disease was not corroborated. ${ }^{10}$ Here, we confirm that the deletion of $8 p$ is frequent in MCL and is associated with leukemic dissemination and with BM disease. Array CGH delineated a commonly deleted region of $1.5 \mathrm{Mb}$ in $8 \mathrm{p} 21.3$ encompassing the TRAIL receptor gene cluster in about $25 \%$ of patients with MCL and cell lines, which was also common in other B-NHL subtypes. Based on these findings, we performed gene expression cDNA microarrays and cell surface protein in a panel of MCL cell lines as well as in other B-NHL cell lines of different origins (F.R.-M., R.S., J.C., D.P., M.J.S.D., and J.A.M.-C., manuscript submitted). These measurements revealed preferential down-regulation of the proapoptotic TRAIL DR5 receptor in lymphomas with monoallelic $8 \mathrm{p}$ loss. However, mutation screening and promoter methylation analysis excluded gene inactivation of nondeleted alleles, indicating that reduced DR5 expression was possibly caused by genomic deletion. These data suggest that DR5 may have tumor suppressor activity in MCL and in other B-NHLs.

In the series, array CGH confirmed that the deletion of chromosomes 9p21.3 at P16/INK4a gene and 17p13.1 at TP53 was correlated with shorter survival. ${ }^{15-18}$ In addition, the deletion of 9q21-q22 represented a novel marker for inferior survival. The favorable prognostic genomic signature included the deletion of $1 \mathrm{p} 21$, which was present in $50 \%$ of the 5-year long-term survivors, but none showed deletions of 9q21-q22, 9p21.3-P16/INK4a, or 17p13.1-TP53. These data provide an initial example of how genomic profiling of tumor cells using array-based CGH methods may be clinically useful in MCL and possibly in other B-NHL subtypes. We propose that the screening of a reduced clone set covering the abnormal chromosomal regions associated with survival (1p21, 9q21-q22, 9p21.3, and 17p13.1) either by FISH or a custom-made array CGH device could be reliably applied to the clinical diagnostics of MCL, such as in the case of B-CLL. ${ }^{14,43}$ Our study also implicates novel regions of imbalance in MCL genomes that may harbor oncogenes and suppressor genes involved in the pathogenesis of this lymphoma.

\section{Acknowledgments}

We thank Drs E. Sarsotti, M. J. Terol, I. Benet, and I. Marugan (Hospital Clinico, Valencia) for assistance with molecular and flow cytometry analyses; Profs M. García-Granero (University of Navarra) and F. Martínez (University of Valencia) for statistical analyses; Dr E. Campo (Hospital Clinico, Barcelona) for pathology review of selected cases; Drs F. Camacho (CNIO, Madrid), P. Algara (Hospital Toledo), M. Gonzalez and J. M. Hernandez-Rivas (Hospital Clinico, Salamanca), I. Navarro, A. Carral (Hospital Sagunto), M. A. Ruiz (Hospital Gandía), M. Monteagud (Hospital Vinaroz), and F. Ortuño (Hospital Morales Mesegeur, Murcia) for providing patient samples and clinical data; and Drs E. L. Karran (Leicester, United Kingdom), A. Turhan (Paris, France), and A. Karpas (Cambridge, United Kingdom) for providing cell lines 


\section{References}

1. Campo E, Raffeld M, Jaffe ES. Mantle-cell lymphoma. Semin Hematol. 1999;36:115-127.

2. Harris NL, Jaffe ES, Diebold J, et al. The World Health Organization classification of hematological malignancies report of the Clinical Advisory Committee Meeting, Airlie House, Virginia, November 1997. Mod Pathol. 2000;13:193-207.

3. Lovec H, Grzeschiczek A, Kowalski MB, Moroy T. Cyclin D1/bcl-1 cooperates with myc genes in the generation of B-cell lymphoma in transgenic mice. EMBO J. 1994;13:3487-3495.

4. Monni O, Oinonen R, Elonen E, et al. Gain of $3 q$ and deletion of 11q22 are frequent aberrations in mantle cell lymphoma. Genes Chromosomes Cancer. 1998;21:298-307.

5. Bea S, Ribas M, Hernandez JM, et al. Increased number of chromosomal imbalances and highlevel DNA amplifications in mantle cell lymphoma are associated with blastoid variants. Blood. 1999;93:4365-4374

6. Bentz M, Plesch A, Bullinger L, et al. t(11;14)positive mantle cell lymphomas exhibit complex karyotypes and share similarities with B-cell chronic lymphocytic leukemia. Genes Chromosomes Cancer. 2000;27:285-294.

7. Martinez-Climent JA, Vizcarra E, Sanchez D, et al. Loss of a novel tumor suppressor gene locus at chromosome $8 \mathrm{p}$ is associated with leukemic mantle cell lymphoma. Blood. 2001;98:34793482.

8. Allen JE, Hough RE, Goepel JR, et al. Identification of novel regions of amplification and deletion within mantle cell lymphoma DNA by comparative genomic hybridization. Br J Haematol. 2002;116: 291-298.

9. Au WY, Gascoyne RD, Viswanatha DS, Connors JM, Klasa RJ, Horsman DE. Cytogenetic analysis in mantle cell lymphoma: a review of 214 cases. Leuk Lymphoma. 2002;43:783-791.

10. Kohlhammer H, Schwaenen $\mathrm{C}$, Wessendorf $\mathrm{S}$, et al. Genomic DNA-chip hybridization in $\mathrm{t}(11 ; 14)$ positive mantle cell lymphomas shows a high frequency of aberrations and allows a refined characterization of consensus regions. Blood. 2004; 104:795-801.

11. Tagawa H, Karnan S, Suzuki R, et al. Genomewide array-based CGH for mantle cell lymphoma: identification of homozygous deletions of the proapoptotic gene BIM. Oncogene. 2005;24:13481358.

12. Schraders $M$, Pfundt $R$, Straatman $H M$, et al. Novel chromosomal imbalances in mantle cell lymphoma detected by genome-wide array-based comparative genomic hybridization. Blood. 2005; 105:1686-1893

13. Werner CA, Dohner H, Joos $\mathrm{S}$, et al. High-level DNA amplifications are common genetic aberrations in B-cell neoplasms. Am J Pathol. 1997;151: 335-342.

14. Dohner H, Stilgenbauer S, Benner A, et al. Genomic aberrations and survival in chronic lymphocytic leukemia. N Engl J Med. 2000;343:1910-1916.

15. Hernandez L, Fest T, Cazorla M, et al. p53 gene mutations and protein overexpression are associated with aggressive variants of mantle cell lymphomas. Blood. 1996;87:3351-3359.

16. Dreyling $\mathrm{MH}$, Bullinger $\mathrm{L}$, Ott $\mathrm{G}$, et al. Alterations of the cyclin D1/p16-pRB pathway in mantle cell lymphoma. Cancer Res. 1997;57:4608-4614.

17. Pinyol M, Hernandez L, Cazorla M, et al. Deletions and loss of expression of p16INK4a and p21Waf1 genes are associated with aggressive variants of mantle cell lymphomas. Blood. 1997; 89:272-280.

18. Greiner TC, Moynihan MJ, Chan WC, et al. p53 mutations in mantle cell lymphoma are associated with variant cytology and predict a poor prognosis. Blood. 1996;87:4302-4310.

19. Kienle D, Krober A, Katzenberger T, et al. VH mutation status and VDJ rearrangement structure in mantle cell lymphoma: correlation with genomic aberrations, clinical characteristics, and outcome. Blood. 2003;102:3003-3009.

20. Stokke $T$, DeAngelis $P$, Smedshammer L, et al. Loss of chromosome 11q21-23.1 and 17p and gain of chromosome $6 p$ are independent prognostic indicators in B-cell non-Hodgkin's lymphoma. Br J Cancer. 2001;85:1900-1913.

21. Orchard J, Garand R, Davis Z, et al. A subset of $t(11 ; 14)$ lymphoma with mantle cell features displays mutated IgVH genes and includes patients with good prognosis, nonnodal disease. Blood. 2003;101:4975-4981.

22. Snijders AM, Nowak N, Segraves R, et al. Assem bly of microarrays for genome-wide measurement of DNA copy number. Nat Genet. 2001;29: 263-264.

23. Camacho FI, Algara P, Rodriguez A, et al. Molecular heterogeneity in MCL defined by the use of specific $\mathrm{VH}$ genes and the frequency of somatic mutations. Blood. 2003;101:4042-4046.

24. Martinez-Climent JA, Alizadeh AA, Segraves R, et al. Transformation of follicular lymphoma to diffuse large cell lymphoma is associated with a heterogeneous set of DNA copy number and gene expression alterations. Blood. 2003;101: 3109-3117.

25. Sanchez-Izquierdo D, Buchonnet G, Siebert R, et al. MALT1 is deregulated by both chromosomal translocation and amplification in B-cell nonHodgkin lymphoma. Blood. 2003;101:4539-4546.

26. Reiner A, Yekutieli D, Benjamini Y. Identifying differentially expressed genes using false discovery rate controlling procedures. Bioinformatics. 2003; 19:368-375

27. Joos S, Granzow M, Holtgreve-Grez H, et al. Hodgkin's lymphoma cell lines are characterized by frequent aberrations on chromosomes $2 p$ and 9p including REL and JAK2. Int J Cancer. 2003; 103:489-495.

28. Martin-Subero JI, Chudoba I, Harder L, et al. Multicolor-FICTION: expanding the possibilities of combined morphologic, immunophenotypic, and genetic single cell analyses. Am J Pathol. 2002; 161:413-420.

29. de Leeuw RJ, Davies JJ, Rosenwald A, et al.
Comprehensive whole genome array CGH profiling of mantle cell lymphoma model genomes. Hum Mol Genet. 2004;13:1827-1837.

30. Bea S, Tort F, Pinyol M, et al. BMI-1 gene amplification and overexpression in hematological malignancies occur mainly in mantle cell lymphomas. Cancer Res. 2001;61:2409-2412.

31. Rosenwald A, Wright G, Wiestner A, et al. The proliferation gene expression signature is a quantitative integrator of oncogenic events that predicts survival in mantle cell lymphoma. Cancer Cell. 2003;3:185-197.

32. Martinez N, Camacho FI, Algara P, et al. The molecular signature of mantle cell lymphoma reveals multiple signals favoring cell survival. Cancer Res. 2003;63:8226-8232.

33. Schaffner C, Idler I, Stilgenbauer S, Dohner H, Lichter P. Mantle cell lymphoma is characterized by inactivation of the ATM gene. Proc Natl Acad Sci U S A. 2000;97:2773-2778.

34. Mailand N, Lukas C, Kaiser BK, Jackson PK, Bartek J, Lukas J. Deregulated human Cdc14A phosphatase disrupts centrosome separation and chromosome segregation. Nat Cell Biol. 2002;4:317-322.

35. Kwong YL, Ha SY, Ching LM, Chan LC. Interstitial deletion of $9 q$ revisited. Leuk Lymphoma. 1993; 12:153-155.

36. Freie B, Li X, Ciccone SL, et al. Fanconi anemia type $C$ and p53 cooperate in apoptosis and tumorigenesis. Blood. 2003;102:4146-4152.

37. Campo E. Genetic and molecular genetic studies in the diagnosis of B-cell lymphomas I: mantle cell lymphoma, follicular lymphoma, and Burkitt's lymphoma. Hum Pathol. 2003;34:330-335.

38. Jacobs JJ, Kieboom K, Marino S, DePinho RA, van Lohuizen $\mathrm{M}$. The oncogene and Polycombgroup gene bmi-1 regulates cell proliferation and senescence through the ink4a locus. Nature. 1999;397:164-168.

39. Sun Z, Arendt CW, Ellmeier W, et al. PKC-theta is required for TCR-induced NF-kappaB activation in mature but not immature T lymphocytes. Nature. 2000;404:402-407.

40. Schlette E, Lai R, Onciu M, Doherty D, BuesoRamos C, Medeiros LJ. Leukemic mantle cell lymphoma: clinical and pathologic spectrum of twenty-three cases. Mod Pathol. 2001;14:11331140.

41. Bigoni R, Cuneo A, Milani R, et al. Secondary chromosome changes in mantle cell lymphoma: cytogenetic and fluorescence in situ hybridization studies. Leuk Lymphoma. 2001;40:581-590.

42. Jarosova M, Papajik T, Holzerova M, et al. High incidence of unbalanced chromosomal changes in mantle cell lymphoma detected by comparative genomic hybridization. Leuk Lymphoma. 2004; 45:1835-1846.

43. Schwaenen C, Nessling M, Wessendorf S, et al. Automated array-based genomic profiling in chronic lymphocytic leukemia: development of a clinical tool and discovery of recurrent genomic alterations. Proc Natl Acad Sci U S A. 2004;101: 1039-1044. 